\title{
Casino gambling in Switzerland - The legal situation, politics and prospects for prevention and harm reduction
}

\author{
Dombrowski, D ; Uchtenhagen, Ambros ; Rehm, Jürgen
}

\begin{abstract}
In April 2000, a new law came into effect in Switzerland that permits casino gambling with unlimited stakes for the first time since 1921. Casinos can now be run only with a concession granted by a newly established federal agency. In addition to economic and administrative information, each casino applying for a concession has to submit a fully developed "social concept" that includes detailed prevention measures for dealing with people with gambling problems, staff training and evaluation research, which an independent advisory board will control. In the fall of 2001, the first casino concessions will be granted based on the quality of each applicant's overall proposal. The new legislation is creating a unique situation in Switzerland. To reduce the potential harm for gamblers that is associated with new forms of gambling, the legislation should be standardized and continuously optimized. These new measures require evaluation and government control.
\end{abstract}

DOI: https://doi.org/10.4309/jgi.2001.4.18

Posted at the Zurich Open Repository and Archive, University of Zurich

ZORA URL: https://doi.org/10.5167/uzh-94599

Journal Article

Published Version

Originally published at:

Dombrowski, D; Uchtenhagen, Ambros; Rehm, Jürgen (2001). Casino gambling in Switzerland - The legal situation, politics and prospects for prevention and harm reduction. Journal of Gambling Issues, (4):online.

DOI: https://doi.org/10.4309/jgi.2001.4.18 


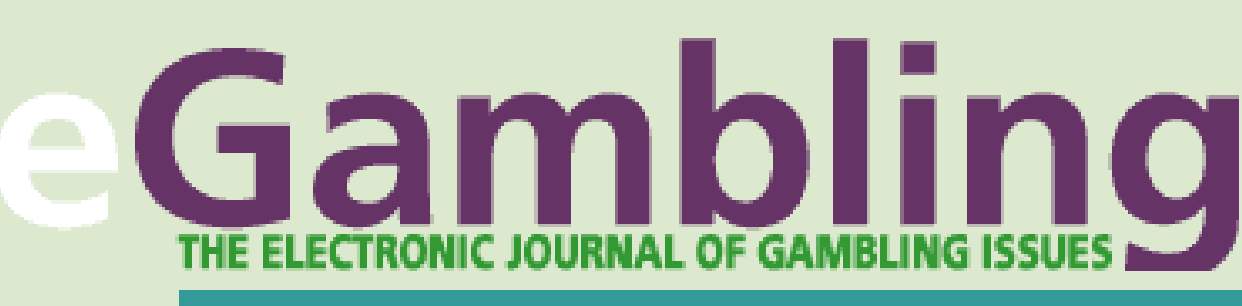

Go to Current Issue

\section{Intro}

\section{policy}

\section{Feature}

Policy

Research

[This article prints out to about 13 pages.]

Profile

Case Study

First Person

Brief Policy Report

Review

Letters

Submissions

Casino Gambling in Switzerland The Legal Situation, Politics and Prospects for Prevention and Harm Reduction

Links

Archive

Subscribe

By Daniela Dombrowski

Addiction Research Institute, Zurich, Switzerland

Ambros Uchtenhagen

Addiction Research Institute, Zurich, Switzerland

Jürgen Rehm

Addiction Research Institute, Zurich, Switzerland University of Toronto, Toronto, Canada

Centre for Addiction and Mental Health, Toronto, Canada

\section{Abstract}


In April 2000, a new law came into effect in Switzerland that permits casino gambling with unlimited stakes for the first time since 1921. Casinos can now be run only with a concession granted by a newly established federal agency. In addition to economic and administrative information, each casino applying for a concession has to submit a fully developed "social concept" that includes detailed prevention measures for dealing with people with gambling problems, staff training and evaluation research, which an independent advisory board will control. In the fall of 2001 , the first casino concessions will be granted based on the quality of each applicant's overall proposal.

The new legislation is creating a unique situation in Switzerland. To reduce the potential harm for gamblers that is associated with new forms of gambling, the legislation should be standardized and continuously optimized. These new measures require evaluation and government control.

\section{The Legal Situation}

On April 1, 2000, the new Federal Law on Games of Chance and Casinos (Bundesgesetz iber Glücksspiele und Spielbanken, 1998) came into effect in Switzerland. The law is specified by the Federal Casino Decree (Bundesrä tliche Spielbankenverordnung) and was ratified by the federal government on February 23, 2000 (see <http://www.admin.ch/> for information on Swiss legislation). note 1 This law permits gambling with unlimited stakes in Switzerland. In the corresponding decree, detailed guidelines specify the conditions under which gambling in Switzerland may take place. According to the Swiss legislative process, this law was made possible by a referendum in 1993; three-quarters of the electorate voted in favor of re-establishing casinos with high stakes (a 1920 referendum disallowed gambling in casinos where it had been allowed before 1921). In $1920,55 \%$ of the population had supported the closing of casinos. This change in voting behavior between the 1920s and the 1990s reflects a general trend in market economies to emphasize individual liberties and decision making, which has also affected attitudes toward other public health policies (e.g., alcohol policy) . 
Until the Federal Law on Games of Chance and Casinos came into effect, the maximum stake in gambling had been limited to CHF five per game. Slot machine gambling had different cantonal note 2 (state) laws that controlled the management of the amusement arcades (facilities with only machines) and small casinos. This led to a total banishment of gambling in some cantons (e.g., Zurich) while a relatively high number of machines were distributed to small casinos, amusement arcades and public places such as bars and restaurants in other cantons (e.g., Ticino). Additionally, many grand casinos note 3 in France, Italy, Austria and Germany are situated alongside the Swiss border.

This new federal law distinguishes between two kinds of gambling:

- games of skill (e.g., card games like poker, as well as machine games where the outcome depends to some degree on the skill of the player)

- games of chance that cannot be influenced by the skills of the gambler (e.g., slot machines or one-armed bandits; in the following text they are referred to as "chance amusement machines").

Games of chance will be strictly limited by law to special resorts like casinos and amusement arcades. Every person or legal entity wanting to run a gambling enterprise must apply for a concession from the federal government. The newly formed Federal Swiss Casino Commission note 4 will review the applications and make recommendations to the federal government.

The deadline for applications was September 30, 2000. The commission has promised to take about a year to review and make a decision on the applications. Two different types of concessions will be granted: Type A concessions for grand casinos (these will be taxed less), and Type B concessions for smaller casinos (these will be taxed more). Type A casinos will be allowed to offer 14 different table games with unlimited stakes, jackpots and maximum winnings at all machines. Type B casinos will only be allowed to offer three kinds of table games with limited stakes, jackpots and maximum winnings at all machines.

Taxation will be regulated as follows: Casinos of Type A pay $40 \%$ of their revenues up to CHF 20 million, and for each additional million the taxation rises by $0.5 \%$. Casinos of Type B pay $40 \%$ of their revenues up to CHF 10 million, and for each additional million the taxation rises by $1 \%$. The plan is to evenly distribute the concessions across Switzerland. Type A casinos will only be permitted within a catchment area of a million people or more. Overall, the intended result is to have about two to six Type A casinos and 15 to 20 Type B casinos all over Switzerland. 
Gambling via telecommunications, especially the Internet, is forbidden. In Switzerland however, there are no models for prosecution in case of violation, nor does the law or the decree provide any. Cantonal law will control machines offering games of skill (in contrast to machines that solely depend on chance).

A five-year transitional law came into effect on April 1, 2000 for amusement machines depending solely on chance in both public places (restaurants, bars, waiting lounges, etc.) and amusement arcades, as well as for casinos that already exist. On April 1, 2005, operation of all games of chance amusement machines run by persons or legal entities that have not been granted a concession will be stopped.

\section{The Social Concept - A Nationwide Approach}

\section{The legal basis for a social concept}

In order to obtain a concession on the recommendation of the Swiss Federal Gambling Commission, each applicant is required to meet certain standards concerning

- measures for prevention and harm reduction of pathological and problem gambling,

- proper training of the casino staff, and

- provision of data for research.

Each applicant must describe in detail in a social concept how these criteria will be fulfilled.

These very strict requirements laid down by federal law create a peculiar situation; systematic, preventive and harm reduction measures have to be introduced nationally and at the beginning of grand casino gambling in Switzerland. To our knowledge, these are unique prerequisites in a nation 
legalizing gambling.

\section{Experiences in other countries}

Most countries that allow large-scale gambling lack systematic, nationwide regulation for preventive measures. Though internationally there has been an increase in gambling policy development in both public and private sectors, the level of interest and the funds available for education, prevention and treatment have not kept pace with increases in legal gambling revenues or in the availability of gambling .

In some Canadian provinces, in Germany, Sweden and the U.S., as well as in some states in Australia, the government grants money for prevention, treatment and research. For instance, two U.S. federal health agencies: the National Institute of Health, and the Substance Abuse and Mental Health Services Administration have allocated funds for research and services. However, "the level of funding is often minuscule compared to similar programs for mental health, substance abuse, and other human services."

In other countries, governments do not engage in funding prevention and harm reduction measures at all. There may be some private funding either in addition to or instead of public funding. In the U.S. and the Netherlands, the private enterprises running casinos have started several initiatives. In the U.S., the gaming industry became active in the field of underage and problem gambling during the 1990s. The American Gaming Association (AGA) founded and financially supports the National Center of Responsible Gaming (NCRG), which grants funds to research projects carried out by academic institutions in North America, and to organizations providing counseling for underage and problem gambling.

In the Netherlands, gambling was legalized in 1975 and the government granted Holland Casino's exclusive rights to run casinos in the Netherlands. Part of the corresponding regulations asked for a prevention concept. Holland Casino's and VAN (the Dutch amusement machine industry) are co-operating with Jellinek Consultancy (a counseling and prevention service linked to the Amsterdam Institute for Addiction Research - Jellinekhuis) to provide prevention and harm reduction measures.

Together, they worked out a prevention plan that includes

- the display of brochures with guidelines for responsible gambling 
- information about the odds of winning and losing in the casinos

- the possibility of suspending people who have gambling problems, and

- a training program for casino and amusement arcade employees, social workers and relatives on how to deal with those who have gambling problems.

In addition to the legal casinos, there are an estimated 40 to 50 illegal casinos ; most of the gambling in Dutch casinos remains uncontrolled. Furthermore, innumerable slot machines are located in eating establishments and amusement arcades throughout the Netherlands. In an attempt to reduce uncontrolled gambling opportunities, the number of amusement machines in public places was reduced, but interestingly, the number of lotteries rose at the same time. Preventive measures for amusement machines, lotteries and illegal casinos are carried out in a non-standardized way, if they are carried out at all: meaning, they do not co-operate with the Jellinek Consultancy.

The Dutch example seems to indicate that government funding for prevention and harm reduction may not be necessary and could be replaced by funding provided by the sector itself. Such efforts have to be regulated; however, it is not only government regulations that are important, but also their enforcement. If most of the casinos are not participating in a standardized, national approach, the result will not be effective.

\section{The implementation of social concepts in Switzerland}

There will probably not be a standardized concept for all casinos in Switzerland as the applicants for a concession had to submit a fully developed social concept of their own. Until the concessions are granted in fall of 2001, the applicants are effectively in competition with each other, which makes exchanging concepts and ideas highly unlikely. However, each submission is bound to contain what's required by law since the granting of the concessions will be based on quality, along with other factors such as location, local traffic and size of the catchment area. Because competition is tough, it is expected (and hoped by some) that a well-planned social concept could mean winning the bid. 
advisory board will supervise the translation of its concept into action. Depending on the concept, its members will often be independent experts from the therapy, social services and research fields, but will also sometimes include casino executives. The advisory boards will report directly to the Swiss Federal Casino Commission.

Last but not least, the law in Switzerland creates a unique chance to collect research; providing data for research is part of the social concept.

Implementing grand casinos in a country where gambling had been strictly limited has been rarely evaluated until now (see Room, Turner \& Iolamiteanu, 1999 for an exception) and could be especially interesting for other countries that also wish to legalize gambling. Furthermore, comparing development in cantons where gambling had been totally abolished, and development in cantons where gambling had already taken place might prove to be interesting. However, most evaluations will require baseline data (e.g., the current level of problem gambling) in order to be able to interpret results and make valid conclusions. Unfortunately, such data has been lacking so far.

\section{An Example of a Social Concept in Switzerland: The Social Concept of Grand Casino SA}

The Addiction Research Institute in Zurich has developed a social concept that the Grand Casino SA and its partners (ACE Admiral Casino \& Entertainment AG, Escor AG, German Casino Management Group) will use to apply for concessions for 10 different casinos (two of Type A, eight of Type B) all over Switzerland. To obtain a concession, the casinos have agreed to subscribe to this social concept outlined below.

After the legal requirements, the social concept has the following components:

- preventive measures

- plans for dealing with problem gambling

- training program for staff 
- research

- social advisory board.

The preventive measures are divided into primary and secondary prevention. Key elements for primary prevention include information and sensitization campaigns for casino customers and the public, a Web site with relevant information, media prevention campaigns, information on odds and pathological gambling, and contact information for professional help. Information brochures and advice on responsible gambling will be openly available in the casinos. Advertising for gambling will be strictly limited. In addition, structural changes to the casino will be made: an ID control at the entrance will prevent the admission of adolescents under 18 or suspended problem gamblers. Although credit cards will be accepted, no cash dispensers will be placed in the casino and no loans will be granted to customers. To prevent staff from relying on tipping, a relatively high fixed wage will be administered, increasing their monthly allowance and allowing them to be freer and less biased when intervening with those who have problems.

As part of secondary prevention, checklists for self-diagnosis will be displayed and combined with the offer of counseling by specially trained staff in each casino. A toll-free, 24-hour telephone hotline will provide the caller with information (e.g., where to obtain professional help). Customers who feel in danger of losing control will be able to have themselves suspended from either their favorite casino or every casino across the country.

To help deal with those who have gambling problems, staff will be trained to speak with customers who are obviously having trouble. A first counseling session may be held in the casino and contact information for professional help will be provided. Problem gamblers can be suspended nationwide, even if they do not agree to that intervention. A fund supplied by the casinos' revenues and managed by the social advisory board will be established for people with gambling problems with financial problems, who wish to immediately enroll in therapy.

All casino staff will be trained in a three-day workshop before starting their job. Training will include information about pathological gambling, risk and protective factors, different types and stages of gambling problems, preventive measures and therapy for problem gamblers. Potential problematic 
behaviors because of any addiction will be thoroughly examined, and social competencies in dealing with problem gamblers will be practised in roleplaying. Staff will be retrained annually. Additionally, at least one supervisor will receive extra training in how to interact with problem customers. He or she will also receive regular professional supervision.

Research will focus on data collection and interpretation of gambling frequencies, the socio-demographic characteristics of casino customers, the frequencies and circumstances of suspensions, and customer turnover in the casinos. Ideally, there would be national or even international monitoring, which however, depends on the co-operation of the other casinos and government regulations. Furthermore, the effectiveness of the preventive measures and social consequences in regions around the casinos will be evaluated by studying hotline usage, co-operating therapy and counseling centers, social services and crime rates.

The social advisory board will consist of seven independent experts from the prevention, therapy, social services and research fields. Up to two casino executives will be allowed to participate in the meetings (without the right to intervene or vote). The board's main function will be to supervise the implementation and realization of the social concept and to report regularly to the Swiss Federal Casino Commission. It will examine, authorize, order and control the preventive measures, training, research and public relations. It will decide upon suspensions and have authorization to grant funds for therapeutic aids for pathological and problem gambling.

Until now, the phenomenon of problem gambling has hardly been studied in Switzerland on a large scale. With the financial support of Loterie Romande and Romande des Jeux SA (i.e. representatives of the gaming industry in the French-speaking part of Switzerland), one major study was carried out in 1998 that estimated the existing prevalence of pathological and problem gambling in Switzerland. The authors screened a representative sample of the adult population for each Swiss region with the SOGS for current problem gambling and found that $0.8 \%$ of the Swiss population were probable pathological gamblers and another $2.2 \%$ were potential pathological gamblers. These prevalence figures are slightly higher than the corresponding Swedish figures. This comparison is justified as Sweden is also about to open casinos, with the first expected to be opened in spring 2001.

In addition, the Swiss study also found a relationship between gambling and alcohol problems; the latter screened by the CAGE . The study showed a positive relationship between the availability of gambling and the prevalence of problem gambling: the higher the relative density of amusement machines per 1000 inhabitants, the higher the prevalence of probable and potential 
pathological gamblers.

When comparing those with gambling problems to the total population these statistics emerged; for all sets of figures, the first percentage is that of problem gamblers and the second percentage is for the total population: $73 \%$ of the group with gambling problems were male, while only $49 \%$ of the total population was male. Those under the age of 29 were $43 \%$ of those with gambling problems, but only $20 \%$ of the total population; $76 \%$ of problem gamblers were employees compared to $55 \%$ of the total population; full time workers composed $79 \%$ of the problem gamblers compared to $52 \%$ of the total population. Among people with gambling problems $18 \%$ were of nonSwiss nationality, compared to being $8 \%$ of the total population; and $48 \%$ of the problem gamblers were unmarried, compared to $30 \%$ unmarried among the total population. A smaller group of gamblers with problems was in the lowtax category ( $13 \%$ vs $29 \%$ ), Protestant $(28 \%$ vs $46 \%$ ) or spoke French as their mother tongue ( $7 \%$ vs $18 \%$ ) compared to the total population.

The number of probable pathological gamblers in Switzerland is estimated to be between 33,000 and 78,000 ; the number of potential pathological gamblers is between 107,000 and 180,000. These numbers are at the lower end of the international problem gambling statistics (Evans \& Hausamann, 1998), (Henriksson in press), (Petry \& Armentano, 1999), (Shaffer, Hall \& Vander Bilt, 1999), (Ladouceur, 1996), (Volberg, 1996), (Osiek, Bondolfi, et al., 1998), although grand casino gambling has not yet started in Switzerland. Thus, problem gambling already exists in Switzerland despite the strict restrictions that have been in force until now.

Although there are exceptions, international and Swiss results show higher rates of problem gambling in regions with more gambling opportunities. This leads to the expectation that there will be rising numbers of problem gamblers following the implementation of grand casino gambling in Switzerland. We believe that a well-founded harm reduction policy should be in place to deal with this expected increase.

\section{Conclusion}

The new legislation has created a unique situation in Switzerland regarding grand casino gambling. While gambling with unlimited stakes will become daily business in Switzerland in the near future, the casinos themselves will be legally required to implement effective prevention methods and to establish a network of consultation and therapy for problem gambling. The Swiss law 
limits gambling activities strictly to casinos and forces each of the casinos to implement and carry out a social concept with detailed a priori stated prevention measures, measures for dealing with problem gamblers, training of staff, and associated evaluation research. An independent social advisory board will control the actual implementation and realization of the measures.

In spite of these precautions, an increase in the prevalence of pathological gamblers is expected in Switzerland. So far, this prevalence rate is at the lower end of the international statistics, but national and international research has shown that the number of people with pathological levels of gambling problems tends to rise with more gambling opportunities.

This calls for a thorough harm reduction approach. To optimize its effectiveness, standardization of the measures and strict evaluation will be very important. It also requires commitment from the government to continue the regulation and control of all the steps. As we learned from the Dutch example, not only will control and regulation be necessary, but also enforcement of the regulations.

There are currently different social concepts in Switzerland that may differ in their effectiveness. It would be in the interest of the Swiss government to put the onus on the casinos to provide evidence for the effectiveness of their concepts. This seems to be particularly possible in a situation when a new law is being implemented.

Traditional medicine and public health have often encountered the problem that evidence of effectiveness is often established post hoc, taking into account many historical aberrations. These problems could be avoided if evidence of the effectiveness of countermeasures is presented at the beginning of the implementation. By routine monitoring and conducting standardized comparative evaluations of the effectiveness of different social concepts, such concepts could be shaped, and ineffective concepts could be abandoned or improved. Therefore, social and public health problems related to gambling in Switzerland might be less dramatic than would otherwise be expected.

\section{References}

Dombrowski, D., Gschwend, P., Steffen, T., Rehm, J. \& Uchtenhagen, A. (2000).

Spielbanken. Ausführungen und Materialien zum Sozialkonzept. Züich: 
Institut für Suchtforschung.

Evans, B. \& Hausamann, P. (1998).

Gambling Addiction. Available:

$<$ http://medicineau.net.au/clinical/psychiatry/psychiatry1.html>.

Ewing, J. (1984).

Detecting alcoholism: The CAGE Questionnaire. Journal of the American Medical Association, 252, 1905-1907.

Henriksson, L.E. (in press).

Government, gambling and healthy populations. Also available in an earlier version at: <http://www.ccsa.ca/ADH/henriksson.htm>.

Ladouceur, R. (1996).

The prevalence of pathological gambling in Canada. Journal of Gambling Studies, 12(2), 129-141.

Lesieur, H. \& Blume, S. (1987).

The South Oaks Gambling Screen (SOGS): A new instrument for the identification of pathological gamblers. American Journal of Psychiatry, 144, 1184-1188.

Osiek, C., Bondolfi, G. \& Ferrero, F. (1998).

Etude de Prévalence du Jeu Pathologique en Suisse. Lausanne: La Romandie Des Jeux SA \& La Loterie Romande.

Petry, N.M. \& Armentano, C. (1999).

Prevalence, assessment, and treatment of pathological gambling: A review. Psychiatric Services, 50, 1021-1027.

Rehm, J. (1999).

Draining the ocean to prevent shark attacks? The empirical foundation of alcohol policy. Nordisk Alkohol \& Narkotikatidskrift (English Supplement), 16, 46-54.

Rehm, J. \& Strack, F. (1994).

Kontrolltechniken. In T. Herrmann \& W.H. Tack (Eds.), Methodologische Grundlagen der Psychologie: Enzyklopä die der Psychologie. Forschungsmethoden, Band 1, 508-555. Gätingen: Hogrefe.

Remmers, P. (1996). 
Der spezielle prä ventive Ansatz zum Problemspielen in den Niederlanden. Sucht, 42, 438-443.

Rönberg, S., Volberg, R.A., Abbott, M.W., Munck, I., Moore, W.L., Jonsson, J., Nilsson, T. \& Svensoson, O. (1999).

Gambling and Problem Gambling in Sweden. Stockholm: National Institute of Public Health.

Room, R., Turner, N. \& lolamiteanu, A. (1999).

Community effects of the opening of the Niagara Casino. Addiction, 94, 1449-1466.

Shaffer, H., Hall, M. \& Vander Bilt, J. (1999).

Estimating the prevalence of disordered gambling behavior in the United States and Canada: A research synthesis. American Journal of Public Health, 89(9), 1369-1376.

This brief policy report was peer-reviewed.

Submitted: November 6, 2000

Accepted: March 16, 2001

Address for correspondence:

Daniela Dombrowski

Addiction Research Institute

Konradstr. 32

Postfach 1617

8031 Zürich, Switzerland

Phone: $++41 / 14481169$

Fax: $++41 / 14481170$

E-mail:dombro@isf.unizh.ch

Daniela Dombrowski, Dipl.-Psych., graduated in clinical and pedagogical psychology from the University of Constance, Germany. She has worked with delinquent adolescents, at a graduate school of business administration and in several research projects. Since 1999 she is a project manager at the Addiction Research Institute in Zurich, Switzerland. She and her colleagues developed the social concept for the Grand Casino S.A., Switzerland. 
Ambros Uchtenhagen, MD, PhD, Professor Emeritus in social psychiatry at Zurich University, is chair of the Board for the Addiction Research Institute at Zurich University. He is a member of the WHO Expert Panel on Drugs, and a board member of the European Association on Substance Abuse Research. He has numerous publications in the fields of social psychiatry and the addictions and is co-editor in chief of European Addiction Research.

Jürgen Rehm, PhD, is currently research director at the Addiction Research Institute at Zurich, Senior Scientist on a part time basis at the Centre for Addiction and Mental Health and professor at the Public Health Sciences Department of the University of Toronto. He has published widely on epidemiology, policy and the economics of substance use and abuse.

issue 4 - may 2001

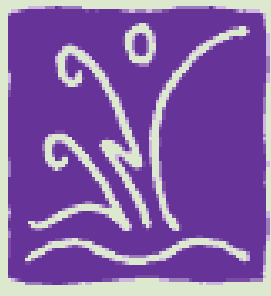

Centre

for Addiction and

Mental Health

Centre de

toxicomanie et

de santé mentale Go to Current Issue

intro | feature | opinion | research | service profile | first person accounts | reviews | letters | archive | submissions | subscribe | links

Copyright (c) 1999-2002 The Centre for Addiction and Mental Health

Please note that these text links will always take you to articles from the current issue of eGambling. Use the navigation bar at the top left of the page to move around within back issues.

Editorial Contact: phil lange@camh.net

Subscribe to our automated announcement list: gamble-on@lists.camh.net

Unsubscribe: gamble-off@lists.camh.net 


\section{Note 1}

See www.admin.ch/ch/d/sr/935 52/index.html for the law and www.admin.ch/ch/d/sr/953 21/index.html for the decree. Both are available in German, French and Italian, unfortunately not in English.

Close this note 
Footnote 2

\section{Note 2}

Switzerland is a federal republic of 26 cantons, which are largely autonomous in terms of their legislation.

Close this note 


\section{Note 3}

According to the Swiss definition, "grand casinos" are casinos with an unlimited number of table games and gambling machines that have unlimited stakes and jackpots. In contrast, "small casinos," already existing in Switzerland, offer a limited variety of games at limited stakes. 